\title{
Activity-dependent modulation of hippocampal synaptic plasticity via PirB and endocannabinoids
}

\author{
Maja Djurisic ${ }^{1} \cdot$ Barbara K. Brott ${ }^{1} \cdot$ Nay L. Saw ${ }^{2} \cdot$ Mehrdad Shamloo $^{2,3} \cdot$ Carla J. Shatz $^{1}$
}

Received: 31 July 2017 / Revised: 21 January 2018 / Accepted: 31 January 2018 / Published online: 18 April 2018

(c) The Author(s) 2018. This article is published with open access

\begin{abstract}
The threshold for Hebbian synaptic plasticity in the CNS is modulated by prior synaptic activity. At adult CA3-CA1 synapses, endocannabinoids play a role in this process, but how activity engages and maintains this retrograde signaling system is not well understood. Here we show that conditional deletion of Paired Immunoglobulin-like receptor B (PirB) from pyramidal neurons in adult mouse hippocampus results in deficient LTD at CA3-CA1 synapses over a range of stimulation frequencies, accompanied by an increase in LTP. This finding can be fully explained by the disengagement of retrograde endocannabinoid signaling selectively at excitatory synapses. In the absence of PirB, the NMDAR-dependent regulation of endocannabinoid signaling is lost, while CB1R-dependent and group I mGluR-dependent regulation are intact. Moreover, mEPSC frequency in mutant CA1 pyramidal cells is elevated, consistent with a higher density of excitatory synapses and altered synapse pruning. Mice lacking PirB also perform better than WT in learning and memory tasks. These observations suggest that PirB is an integral part of an NMDA receptor-mediated synaptic mechanism that maintains bidirectional Hebbian plasticity and learning via activity-dependent endocannabinoid signaling.
\end{abstract}

\section{Introduction}

Recent genome-wide association studies (GWAS) of Schizophrenia, now powered by impressive numbers of patients and controls, have identified the MHC locus (Major Histocompatibility Class I and II; Human HLA) as a major region of association $[1,2]$. Single nucleotide polymorphisms associated with both classical and nonclassical MHC

Electronic supplementary material The online version of this article (https://doi.org/10.1038/s41380-018-0034-4) contains supplementary material, which is available to authorized users.

Maja Djurisic

djurisic@stanford.edu

$\triangle$ Carla J. Shatz

cshatz@stanford.edu

1 Departments of Biology and Neurobiology, and Bio-X, Stanford University, Stanford, CA 94305, USA

2 Behavioral and Functional Neuroscience Laboratory, Stanford University School of Medicine, Stanford, CA 94305, USA

3 Behavioral and Functional Neuroscience Laboratory and Department of Neurosurgery, Stanford University School of Medicine, Stanford, CA 94305, USA class I (MHCI) genes have been reported [1, 2]. In addition, MHCI gene expression and regulation by inflammation and nicotine are altered in the brains of patients with Schizophrenia [3]. Other genes at the HLA locus including components of the complement cascade, as well as MHC class II (HLA-DPA1 and HLA-DRB1), have been associated with schizophrenia, bipolar disorder and major depressive disorder [4-6]. Given their well-known roles in the immune system, these associations have been interpreted to imply that disorders of immune function may contribute to Schizophrenia.

Recently, however, it has become evident that particular MHCI proteins are expressed by neurons and are located at synapses in the healthy brain [7-9]. Also located in the MHC locus are components of the complement cascade, some of which are also expressed in neurons $[4,10]$. Mice lacking $\mathrm{C} 1 \mathrm{q}, \mathrm{C} 4$ or the classical MHCI molecules $\mathrm{H} 2-\mathrm{Db}$ and $\mathrm{H} 2-\mathrm{Kb}$ all share remarkably similar synapse pruning deficits during an early developmental critical period in the visual system $[4,5,11]$. These observations point to a specific function of these molecules at synapses, as well as in the immune system, and suggest molecular mechanisms for the observed changes in synapse and spine density noted in the brains of Schizophrenia patients [12]. 
In the immune system, many MHCI family members act via cognate receptors, generating downstream signaling cascades. Paired Immunoglobulin-like receptor B (PirB; human LilrB2 and 3), an MHCI innate immune receptor [13], is expressed in excitatory pyramidal neurons of the forebrain [14]. In visual cortex of mice lacking PirB, the density of dendritic spines and functional glutamatergic synapses is more than $50 \%$ greater than WT [15]. This elevation in density persists into adulthood and matches closely the normal spine density measured at the onset of developmental synapse pruning [16], demonstrating a role for PirB in pruning [16]. It is not known how PirB regulates pruning, but it is possible to trigger the rapid appearance of new synapses in the brain of adult WT mice by acutely blocking PirB function using a recombinant decoy receptor [17]. Cellular mechanisms of synaptic weakening such as LTD are thought to be necessary for synapse pruning [11, 18, 19]. These mechanisms are best understood at CA3CA1 hippocampal synapses $[19,20]$. Here we examine LTP and LTD in mice with conditional deletions of PirB in hippocampal pyramidal neurons. A shift in the threshold for synaptic plasticity also prompted us to investigate endocannabinoid retrograde signaling, as well as behavior on simple memory tasks.

\section{Materials and methods}

All experiments were carried out in accordance with the Guide for the Care and Use of Laboratory Animals of the National Institutes of Health and approved by the Stanford University Institutional Animal Care and Use Committee. Methods are also in accordance with the Policies of the Society for Neuroscience on the Use of Animals and Humans in Neuroscience Research. All mice were maintained in a pathogen-free environment. No statistical a priori sample size estimate was conducted. Behavioral and physiology studies of germline PirB-/- were all performed and analyzed blind to genotype. Experiments using different PirB fl/fl lines were analyzed blind to genotype, with the exception of an experiment on Pyr-WT vs. Pyr-KO for Fig S9 (C and D) which was both performed and analyzed blind to genotype. All experimental cohorts were block-randomized over time, and test litters were all age-matched and all male. The sampling quota was determined when statistical power was reached.

\section{Experimental model and subject details}

Germline PirB - / - mutant mice, mice with postnatal conditional deletion of PirB, as well as corresponding WT cohorts, were obtained from a PirBfl/fl mouse line crossed with the appropriate Cre-deleter line. Generation of the PirBfl/fl line has been described previously [14], and detailed information is also provided in Supplementary Information (SI). All studies were performed in adult male animals or slices at postnatal day 90 (P90) or older.

Postnatal conditional deletion of PirB from forebrain pyramidal neurons was achieved by crossing PirBfl/fl to a line in which Cre recombinase is under the control of the CamKII $\alpha$ promoter (B6.Cg-Tg(Camk2a-cre)T29-1Stl/J; JAX 005359). For CA3 specific Cre-mediated PirB deletion, the C57BL/6-Tg(Grik4-cre)G32-4Stl/J line was used (JAX 006474). Heterozygous mice (CamKII-Cre; PirB+/fl or Grik4-Cre; PirB+/fl) were bred to obtain litters containing both experimental and control genotypes (CamKIIaCre; PirBfl/fl (Pyr-KO) vs. CamKIIa-Cre; PirB +/+(PyrWT) or Grik4-Cre; PirBfl/fl (CA3-Pyr-KO) vs. Grik-4-Cre; PirB $+/+(C A 3-P y r-W T))$. An automated genotyping service was used (Transnetyx, Inc.). Breeding strategy and genotyping considerations are provided in SI.

\section{Quantification and statistical analysis}

Statistics for each experiment are reported in the accompanying Figure Legends. Data analysis and statistical analyses were performed using SigmaPlot 10.0 (Systat Software Inc.) and IBM SPSS Statistics 23 (IBM Corporation), respectively. Data are reported as mean \pm s.e.m, with sample size given as number of slices or cells along with the number of mice (e.g., $n=x$ slices/y mice); for behavioral experiments only the number of mice is reported. For behavioral and synaptic plasticity experiments, Twoway Anova with repeated measures (2-way RM Anova) was used to test differences between genotypes over time; the reported differences are due to effect of genotype, unless otherwise stated. One-way Anova was used to test differences between baseline and post-induction LTP/LTD period for a single genotype. One-Way Anova with post-hoc Tukey was used when needed to control for multiple comparisons. Data sets were comparable in variance (Levene's test). The effect of plasticity-induction paradigms on fEPSP slopes and Paired Pulse Ratio (PPR) was assessed once a stable change was reached during the post-induction period. For synaptically evoked LTP/LTD, measurements were made starting at 20 min post-induction through the end of the recording period. For chemically induced LTD (e.g., with DHPG or NMDA), averages of fEPSP slopes or PPR were compiled starting at 30 or $40 \mathrm{~min}$ post-induction, as noted. Pairwise Mann-Whitney (U) test (normal distribution not assumed) was also used to compare means where appropriate. All statistical tests were two-tailed. Statistical significance was reached when probability due to chance fell below 5\%; i.e., $p$-value $p<0.05$. Outcomes of statistical tests were reported as exact $\mathrm{p}$ values, unless the probability due to chance fell below $0.1 \%$, in which case it was always denoted as $p<0.001$. 
A

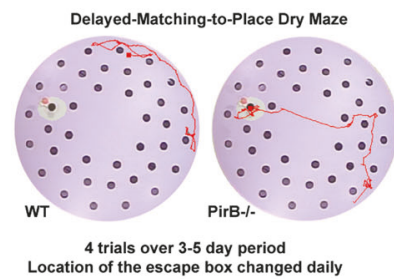

B

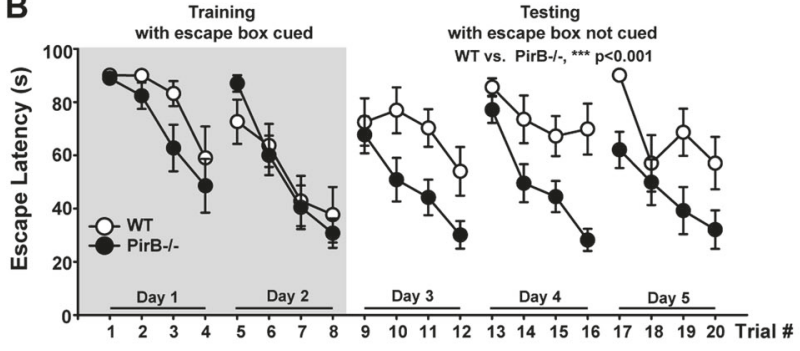

C

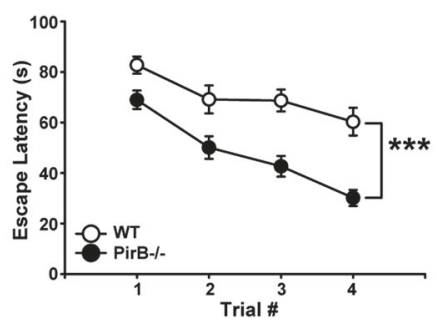

Fig. 1 Faster learning in delayed-match-to-place (DMP) dry maze test in PirB - / - mice. a Photograph of modified Dry Barnes Maze Arena used for DMP task. Each mouse had four trials to find the escape box on each day, over a period of 5 days. Median tracks (red trace) from WT and PirB - /- at Day 4 /Trial 4 are superimposed on maze image; white patch indicates location of escape box. In this trial, WT never finds the box, while PirB-/- is successful. b Plot of escape latencies for 2 days of cued (Day 1, Day 2), followed by 3 days of non-cued (Days 3-5), trials. WT and PirB $-/-$ mice performed the task equally well when a visual cue marked escape box during first two testing days

Detailed methods for delayed match to place behavioral test, hippocampal synaptic physiology, histology, and Western blotting are included in Supplementary Information.

\section{Results}

\section{PirB null mice outperform WT on a delayed match- to-place task}

As a first step in motivating a study of hippocampal synaptic plasticity in mice lacking PirB function (PirB-/-), hippocampal learning and memory were assessed in a delayed-match-to-place task (DMPT) using a modified Barnes dry maze (Fig. 1a) [21]. Intact LTP at hippocampal synapses, and functional NMDA receptors are thought to be needed for memory encoding during this task [22]. Proper execution of DMPT requires mice to form a stable longterm memory of spatial cues used for navigation. At the same time, as the position of an escape hole changes daily, animals have to acquire additional information that is used only for a period of time; this procedural aspect of DMPT is thought to reflect learning flexibility [22].

Both genotypes performed equally well during initial training (Fig. 1b). After the 2-day training period, mice were tested for an additional 3 days (Day 3 to Day 5) using the same visual cues placed around the arena, but now with an unmarked escape box, whose position changed daily. PirB $-1-$ mice performed better than WT, with significantly shorter escape latencies across all trials for Day 3, 4, and 5 (Fig. 1b). Even on the first day (Day 3) of non-cued testing, escape latencies were significantly shorter in PirB-/-, with a 3 fold better performance achieved during the 4th trial on Day 4. A difference in escape latency is also evident when trials were averaged across 3 days of testing (Fig. 1c). Other (gray area on left); $p=0.204$ for WT vs. PirB-/-, 2-way RM Anova. Escape latencies for non-cued trials over the next 3 day period shows steeper learning curves for PirB $-/$ - than WT; performance is almost $3 \times$ better for PirB $-/-$ vs. WT on second day of non-cued trials; $p<$ 0.001 across 3 days of non-cued testing; 2-way RM Anova. c Trials averaged across Day 3, 4, and 5 (non-cued testing) also show significantly better performance by PirB $-/-$ vs. WT; $* * * p<0.001 ; 2-$ way RM Anova. b, c WT (open symbols): $n=8$ mice; PirB-/- (black symbols): $n=13$ mice (See also Fig. S1)

measures such as the time and distance "savings" that mice achieve between the first and last trial of each day were also significantly larger in PirB-/- vs. WT (Fig. S1). Thus, PirB $-/-$ mice successfully acquire a DMP task, and their performance exceeds that of WT, implying that learning capacity on this simple task is restricted by PirB.

It is possible that PirB deletion results in changes in basal synaptic transmission or intrinsic excitability of neurons involved in learning circuitry in hippocampus. Multiple parameters of CA3-CA1 synaptic function known to be implicated in learning and working memory [23-26] were measured, including $\mathrm{I}_{\mathrm{AMPA}} / \mathrm{I}_{\mathrm{NMDA}}$ ratio, kinetics of $\mathrm{I}_{\mathrm{AMPA}}$ and $\mathrm{I}_{\mathrm{NMDA}}$, PPF [27], as well as the firing rate and firing threshold of CA1 pyramidal cells (Fig. S2 A-E). Together, all these parameters of basal synaptic transmission and intrinsic excitability are intact in the absence of PirB. Nevertheless, input/output curves for CA3-CA1 synapses point to an increase in the strength of excitatory synaptic transmission in PirB $-/-$, relative to WT (Fig. S2F). This observation suggests that a perturbation in synaptic transmission such as the presence of more synapses and/or more powerful synapses may underlie the better performance of PirB -/ - on DMPT.

\section{Conditional deletion of PirB in excitatory pyramidal cells abolishes LTD and lowers the threshold for LTP}

Improved hippocampal-dependent learning in mice frequently correlates with larger LTP, and smaller LTD [28, 29]. To assess if Hebbian synaptic plasticity is altered in the absence of PirB, LTP and LTD were studied in acutely isolated hippocampal slices from adult mice (P90-P130). Prior work demonstrated that PirB expression in cerebral cortical pyramidal neurons is required for synaptic pruning [16]. Therefore, we used mice with conditional deletion of 

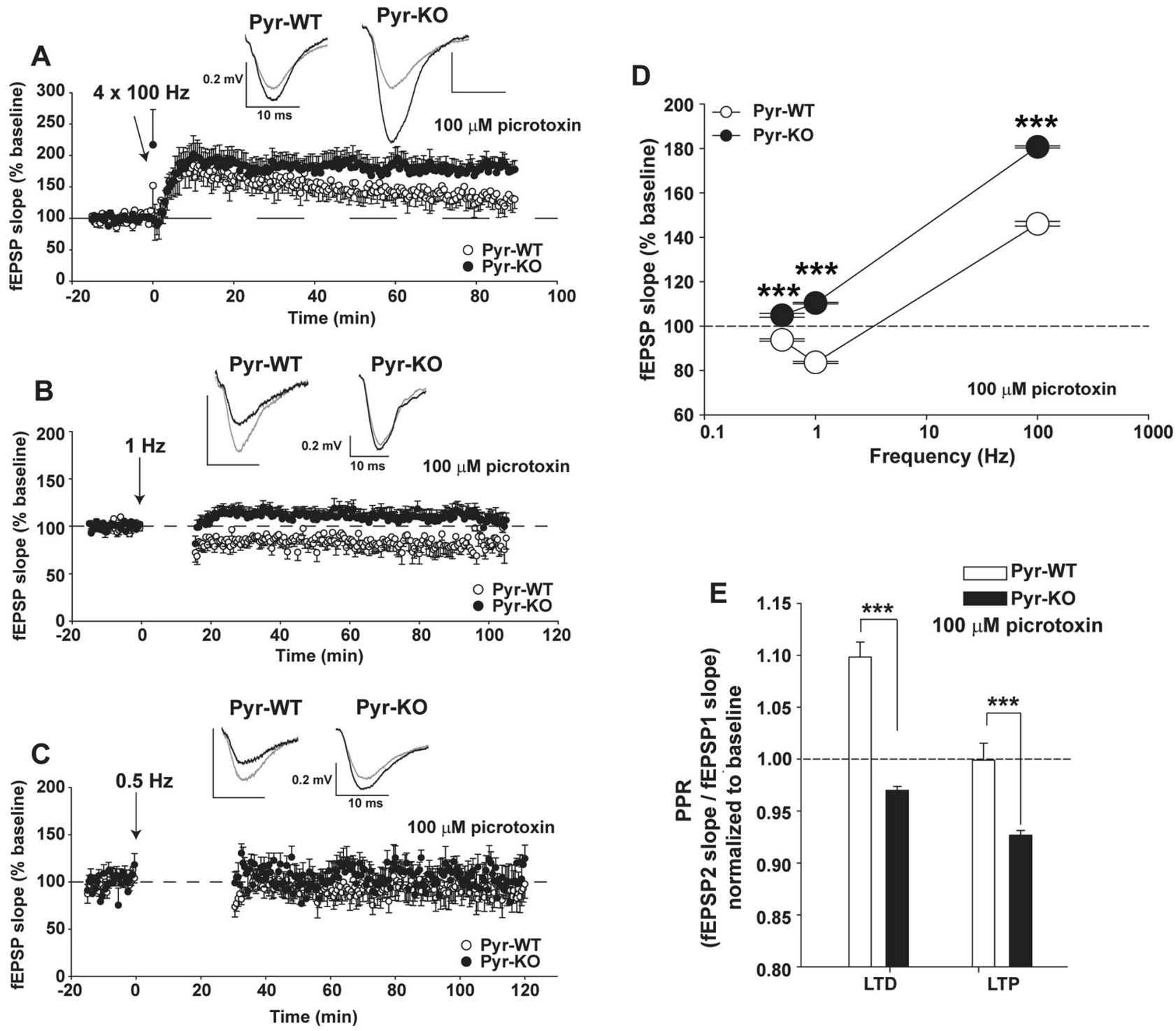

Fig. 2 Deficient LTD and increased LTP with conditional deletion of PirB in forebrain excitatory neurons. a LTP at CA3-CA1 synapses in CamKIIa-Cre; PirB + I + (Pyr-WT) vs. CamKIIa-Cre; PirB fl/fl (Pyr-KO) induced with $4 \times 100$ Hz. Pyr-WT LTP: $146.19 \pm 1.3 \%(n=8$ slices $/ 5$ mice). Pyr-KO LTP: $180.7 \pm 1.35 \%(n=8$ slices $/ 3$ mice); $p<0.001$. b LTD induced with 900 pulses at $1 \mathrm{~Hz}$. Pyr-WT LTD: $83.9 \pm 0.65 \%(n=$ 12 slices/6 mice) vs. Pyr-KO LTD: $110.4 \pm 0.61 \%(n=16$ slices $/ 6$ mice $) ; p<0.001$. c Same as (b), but LTD induction using 0.5 Hz. Pyr-WT LTD $0.5 \mathrm{~Hz}: 93.7 \pm 1.15 \%$ ( $n=9$ slices $/ 5$ mice $)$ vs. Pyr-KO LTD $0.5 \mathrm{~Hz}: 104.8 \pm 1.08 \%(n=5$ slices $/ 3$ mice $) ; p<0.001$. d Summary of LTP and LTD vs. the frequency of induction in Pyr-WT vs. Pyr-KO. Absence of LTD in Pyr-KO is evident for a range of frequencies from 0.5 to $400 \mathrm{~Hz}$. e Bargraphs of average paired-pulse ratios (PPR). Pyr-WT LTD: $1.10 \pm 0.01$ ( $n=12$ slices, 6 mice) vs. Pyr-KO LTD: $0.970 \pm 0.003(n=16$ slices, 6 mice); $p<0.001$. Pyr-WT LTP: $0.999 \pm 0.16$ ( $n=8$ slices, 5 mice) vs. Pyr-KO LTP: $0.927 \pm 0.004$ ( $n=8$ slices, 3 mice $), p<0.001, * * * p<0.001$. Test: 2-Way RM Anova. Mean values are averages of fEPSP slopes or PPR measured between $20-90$ min post-induction. Insets: fEPSP trace examples from Pyr-WT and Pyr-KO slices before (gray line) and after induction (black line) of LTP (a) or LTD (b, c); each trace is average of 30 individual traces taken at baseline or $75-90 \mathrm{~min}$ post-induction.

PirB only from pyramidal neurons [17] (Fig. S3). Conditional mice were generated by crossing $\mathrm{PirBfl} / \mathrm{fl}$ mice with a CamKIIa-Cre deleter line (see SI). For simplicity, the abbreviated names of experimental and control lines used in these experiments are: 1) Pyr-KO for CamKIIa-Cre; PirB fl/ fl, and 2) Pyr-WT for CamKIIa-Cre; PirB $+/+$.
The strength of CA3-CA1 synapses was measured with field potential recordings (Fig. 2). To assess activitydependent strengthening at CA3-CA1 synapses, LTP was induced using 4 trains at $100 \mathrm{~Hz}$. In Pyr-WT, a $145 \%$ increase in fEPSP slope relative to baseline resulted. In adult Pyr-KO littermates, the same induction protocol 
A

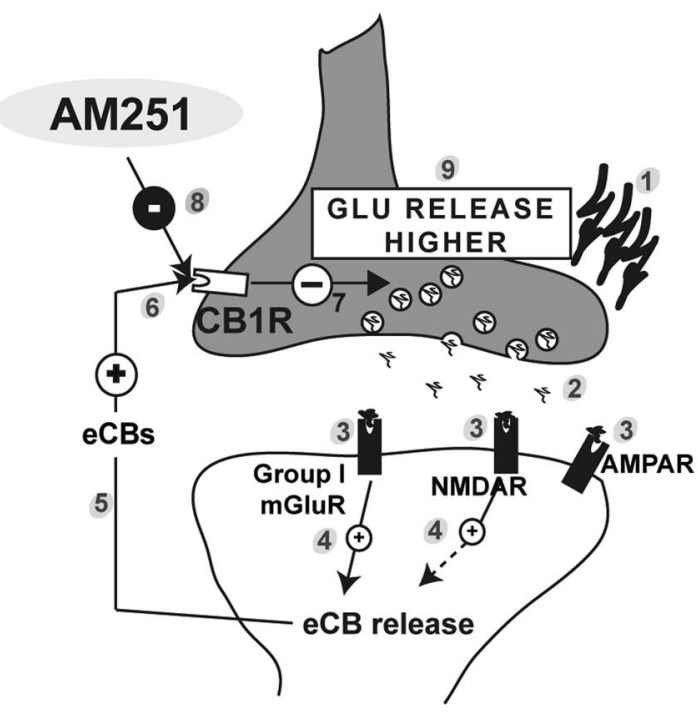

D

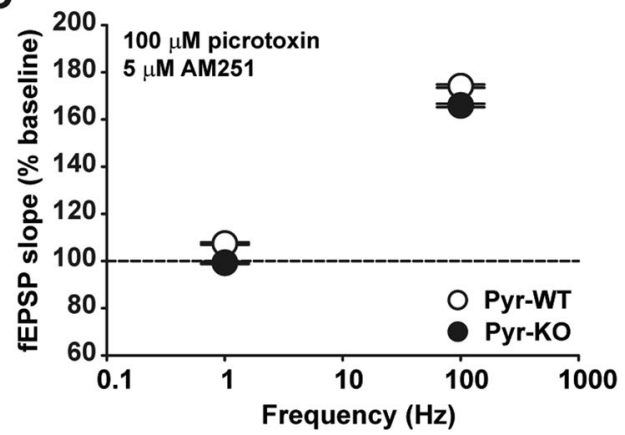

Fig. 3 Blockade of CB1R in Pyr-WT phenocopies LTP and LTD alterations in Pyr-KO. a Cartoon illustrating synthesis and retrograde release of eCBs following a plasticity-inducing stimulus. Synaptic stimulation [1] triggers release of glutamate [2] which binds to postsynaptic AMPAR, NMDAR and Group I mGluRs [3]. Signaling downstream of NMDAR and Group I mGluRs elicits endogenous cannabinoid synthesis (eCBs) and release $[4,5]$, and binding to presynaptic CB1 receptor (CB1R) [6]. CB1R activation decreases neurotransmitter release [7]. Application of AM251 (a CB1R inverse agonist) depresses CB1R activation [8] and generates higher than normal glutamate release [9]. b LTD $(1 \mathrm{~Hz})$ of CA3-CA1 synapses is abolished in Pyr-WT with addition of $5 \mu$ M AM251 (107.4 $\pm 0.57 \%$ baseline; $n=$ 10 slices/4 mice); $1 \mathrm{~Hz}$ stimulation in Pyr-KO in the presence of AM251 resulted in the post-induction fEPSP slope of $99.2 \pm 0.63 \%$ baseline $(n$ $=8$ slices $/ 4$ mice). $\mathbf{c}$ LTP in Pyr-WT in the presence of $5 \mu \mathrm{M}$ AM251 $(174.1 \pm 1.2 \% ; n=13$ slices $/ 5$ mice $)$ increases relative to LTP in

generated significantly larger $(\sim 180 \%)$ and more persistent LTP (Fig. 2a). Next, LTD was induced in Pyr-KO or PyrWT littermates by delivering 900 pulses at $1 \mathrm{~Hz}$. LTD was detected in Pyr-WT. In contrast, LTD was absent in Pyr-KO
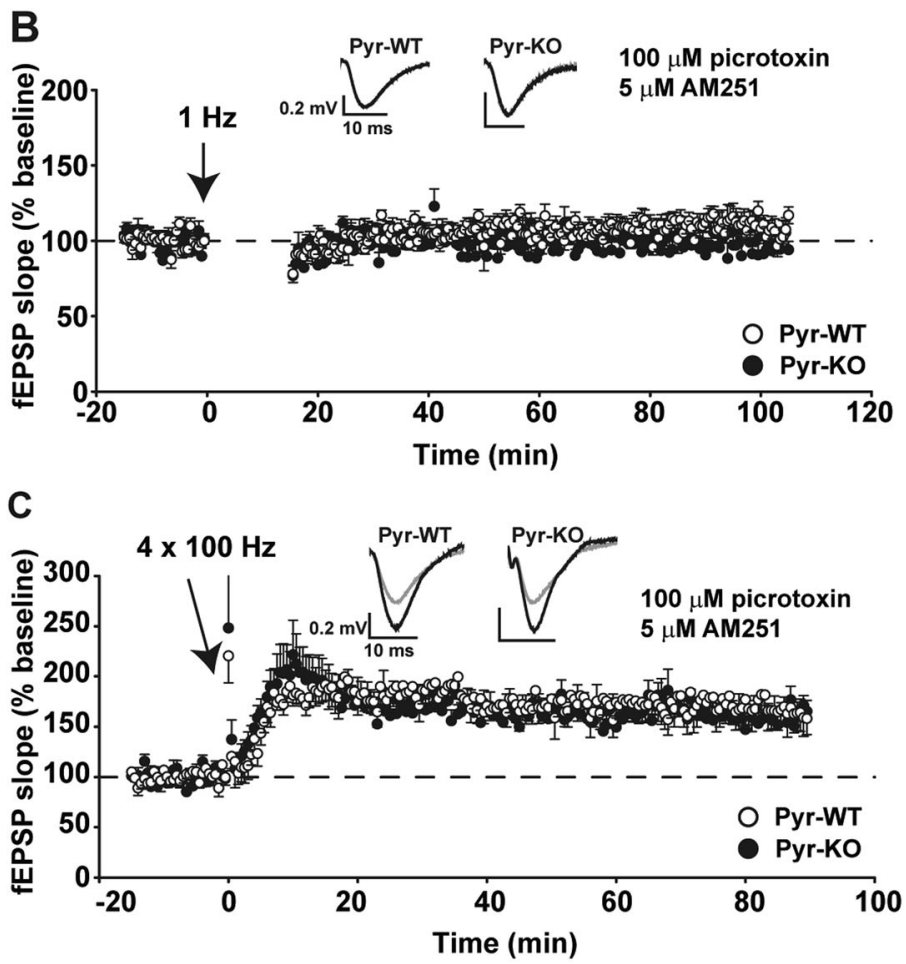

E

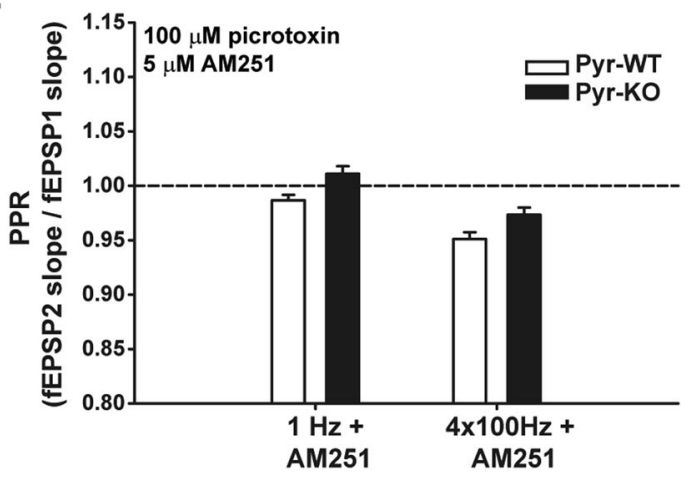

control conditions $(146.19 \pm 1.3 \%$ from Fig. $2 \mathrm{a}, p<0.001$, 2-Way RM Anova), and even slightly surpasses the LTP measured in Pyr-KO in the presence of $5 \mu \mathrm{M}$ AM251 $(165.8 \pm 1.5 \% ; n=8$ slices $/ 3$ mice; $p<0.001$, 2-Way RM Anova). d Summary of LTP and LTD vs. frequency of induction in Pyr-WT vs. Pyr-KO in presence of $5 \mu \mathrm{M}$ AM251. Absence of LTD is now evident in both Pyr-KO and Pyr-WT. e PPR in AM251. Differences in PPR in Pyr-WT vs. Pyr-KO after induction of LTD and LTP seen in control conditions (Fig. 2e) are abolished in the presence of AM251.PPR after $1 \mathrm{~Hz}$ : Pyr-WT $0.99 \pm 0.01(\mathrm{n}=10$ slices/ 4 mice $)$ vs. Pyr-KO, $1.01 \pm 0.01$ ( $n=8$ slices/ 4 mice); $p=0.02$. PPR after $4 \times 100$ Hz: Pyr-WT: $0.95 \pm 0.01(n=13$ slices, 5 mice $)$ vs. Pyr-KO: $0.97 \pm$ 0.01 ( $n=8$ slices, 3 mice); $p=0.015$. Test: 2 -Way RM Anova. Means are averages from 20 to $90 \mathrm{~min}$ post-induction. Insets: fEPSP trace examples from Pyr-WT and Pyr-KO slices before (gray line) or after induction (black line) of LTD (b) or LTP (c); each trace is average of 30 individual traces taken at baseline or at $75-90$ min post-induction.

littermates; instead a small but significant LTP was observed (Fig. 2b).

Both LTP and LTD at CA3-CA1 synapses in WT animals are NMDA-receptor dependent [30, 31]. As 
A

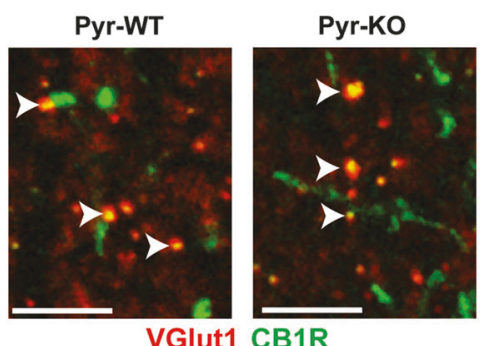

B

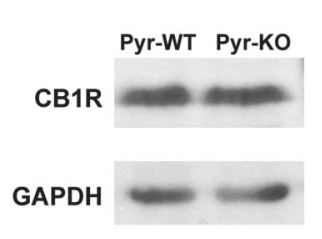

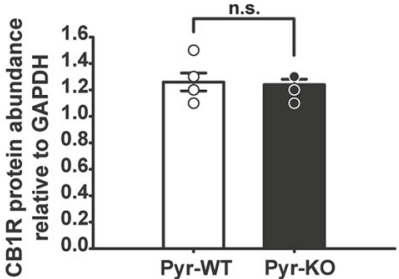
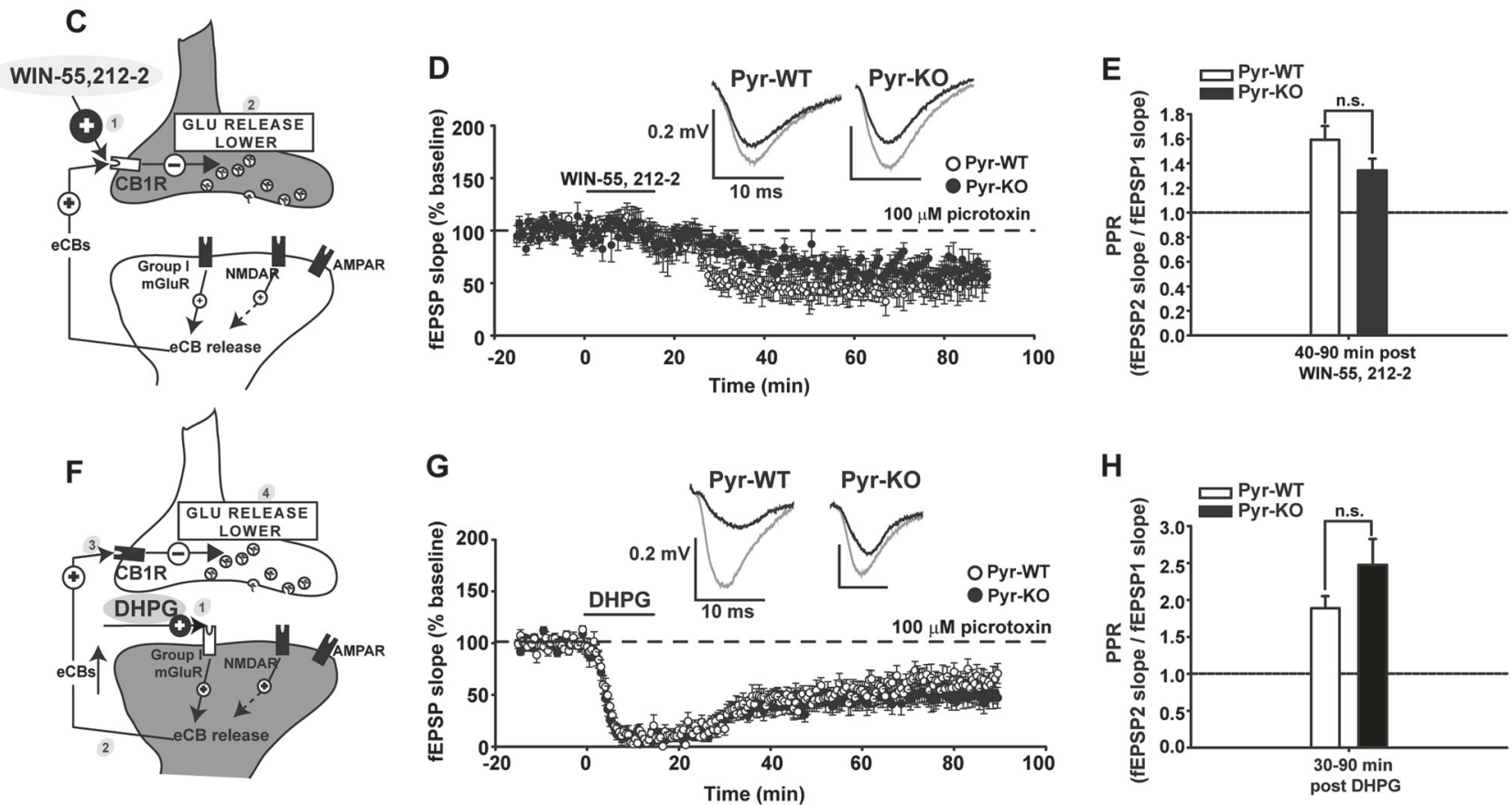

H

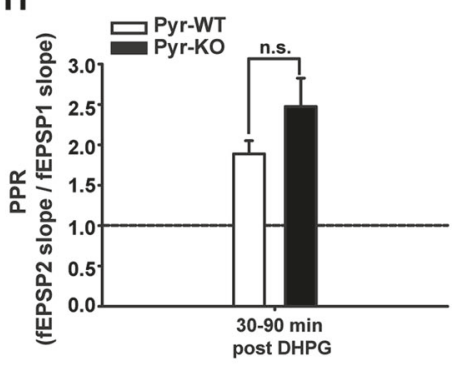

Fig. 4 Activation of CB1R and group I mGluR, obligatory components of endocannabinoid system in CA3-CA1, is similar between PyrWT and Pyr-KO. a Fluorescent micrographs of CA1 St. radiatum from Pyr-WT (left) and Pyr-KO (right) showing VGlut1 (red) and CB1R immunostaining (green). Overlap of the two signals is yellow. No apparent difference is detectable between the two genotypes. Calibration bar: $5 \mu \mathrm{m}$. b Western Blot analysis for CB1R, relative to GAPDH, for Pyr-WT and Pyr-KO. Left-image of a representative gel showing CB1R specific and GAPDH specific bands. Right-bar graph of relative CB1R protein abundance in Pyr-WT $(1.26 \pm 0.07, n=5)$ vs. Pyr-KO $(1.24 \pm 0.04, n=5), p=1.000, U$-test. c Cartoon of CA3CA1 synapse depicting effect of CB1R agonist WIN-55,212-2 [1] on $\mathrm{CB} 1 \mathrm{R}$ activation, resulting in lower glutamate release [2]. d $15 \mathrm{~min}$ bath application of $5 \mu \mathrm{m}$ WIN-55,212-2 generates persistent WINLTD in Pyr-WT $(49.4 \pm 0.95 \% ; n=8$ slices $/ 4$ mice; $p<0.001$ relative to baseline $)$ and Pyr-KO $(65.9 \pm 0.89 \% ; n=7$ slices $/ 3$ mice; $p<0.001$ relative to baseline). e Average PPR for WIN-LTD in Pyr-WT: $1.59 \pm$ $0.11(n=8$ slices/4 mice) vs. Pyr-KO: $1.34 \pm 0.10 \quad(n=7$ slices $/ 3$ mice); $p=0.10$. $\mathbf{f}$ Cartoon depicting effect of Group I mGluR agonist DHPG [1] on eCB release [2], eCB binding to CB1R [3] and lower glutamate release [4]. g $15 \mathrm{~min}$ bath application of $100 \mu \mathrm{m}$ DHPG resulted in prominent DHPG-LTD in both Pyr-WT (53.25 $\pm 0.8 \% ; n$ $=11$ slices $/ 4$ mice; $p<0.001$ relative to baseline; one-way Anova) and Pyr-KO $(45.1 \pm 0.80 \% ; n=11$ slices/ 4 mice; $p<0.001$ relative to baseline; one-way Anova). h Average PPR after DHPG application. During DHPG-LTD (30-90 min post DHPG), PPR in Pyr-WT: $1.89 \pm$ $0.16(n=11$ slices, 4 mice $)$ vs. PPR in Pyr-KO: $2.47 \pm 0.35(n=$ 11 slices, 4 mice); $p=0.621$. 2-Way RM Anova. Insets: fEPSP trace examples from Pyr-WT and Pyr-KO slices before (gray line) and after induction (black line) of WIN-LTD (d) or DHPG-LTD (g); each trace is average of 30 individual traces taken at baseline or at $75-90 \mathrm{~min}$ post-induction. expected, this dependence is seen in Pyr-WT: in the presence of the NMDA receptor blocker D-AP5, both LTP and LTD were abolished (Fig. S4). In Pyr-KO mice, LTP was also abolished with D-AP5, indicating that enhanced LTP is entirely dependent on NMDA receptors.

In the absence of PirB, LTD might still be present at CA3-CA1 synapses, but the threshold for induction could have shifted. To examine this possibility, LTD in Pyr-KO and Pyr-WT littermates was tested again, but at a frequency of $0.5 \mathrm{~Hz}$. At this frequency, induction of LTD in Pyr-WT littermates is observed, but is about $91 \%$ of baseline-not as robust as at $1 \mathrm{~Hz}$, and, similar to previous reports [32]. However, in Pyr-KO the same LTD induction protocol failed to generate LTD and instead resulted in a small, but significant $(p<0.001)$ potentiation-about $104 \%$ above baseline (Fig. 2c). Thus, frequency dependency has shifted 
away from LTD towards LTP in the absence of PirB (Fig. 2d). Together, these results suggest that PirB expression in excitatory neurons in adult hippocampus is needed for bidirectional changes in synaptic strength in an activitydependent and NMDAR-dependent fashion.

\section{Activity-dependent modulation of paired pulse ratio is altered in Pyr-KO}

Since changes in presynaptic function could account for observed alterations in LTP and LTD, paired-pulse ratio (PPR) was monitored continuously both at baseline and following induction of LTP or LTD (Fig. 2e; Fig. S5). PPR is thought to reflect transmitter release, with an increase in PPR associated with lowered glutamate release and vice versa [27, 33]. As expected from previous studies, PPR in Pyr-WT increases following LTD induction [34]. This activity-dependent modulation of PPR is consistent with lower glutamate release [27]. In contrast, in Pyr-KO the same LTD protocol resulted in an unexpected decrease in PPR (Fig. 2e). For LTP, following induction in Pyr-WT, there is no change in PPR, again as expected [35]. In contrast in Pyr-KO, PPR decreased by about 7 \% (Fig. 2e) after LTP induction. It is worth noting that baseline PPR, prior to LTP or LTD induction, is comparable between Pyr-WT and Pyr-KO mice (Fig. S5C), as is between germline PirB-/- vs. WT (Fig. S2D), and thus baseline differences between Pyr-WT and Pyr-KO do not contribute to the change in PPR observed in the post-induction period. In sum, in Pyr-KO there is a paradoxical decrease in PPR following both LTP, as well as LTD (Fig. 2e), suggesting that PirB may contribute to activity-dependent regulation of glutamate release at CA3-CA1 synapses.

\section{Blockade of endocannabinoid receptor CB1R in Pyr- WT phenocopies Pyr-KO LTD and LTP}

At CA3-CA1 synapses, presynaptic release is modulated by retrograde effects of endocannabinoids (eCBs) in an activity-dependent way: eCBs are produced and released from CA1 dendrites using LTP-inducing paradigms $(100 \mathrm{~Hz}$ tetanus or theta burst), and are also critical for induction of both I-LTD throughout the CA1 dendritic tree [36-39] and for LTP at excitatory CA3-CA1 synapses [40]. LTD requires postsynaptic release of eCBs, which in turn decreases glutamate release presynaptically $[34,41]$.

To examine if an eCB-dependent component of plasticity is altered in Pyr-KO, LTD and LTP experiments were repeated in the presence of $5 \mu \mathrm{M}$ AM251, an inverse agonist of CB1R, an endocannabinoid-specific receptor expressed in hippocampus (Fig. 3a) [42]. In Pyr-WT, blockade of CB1R abolished LTD, while LTP increased in size to match that of Pyr-KO. In Pyr-KO, the effect of AM251 was occluded (Fig. 3b, c, d). In addition, the difference in PPR between Pyr-WT and Pyr-KO observed during LTP and LTD in control conditions (Fig. 2e) was abolished with CB1R blockade (Fig. 3e). Together, these results suggest that in Pyr-KO, eCB release and CB1R signaling are disengaged, pointing to a role for PirB in eCB signaling at CA3-CA1 synapses during both LTD and LTP.

\section{Group I mGluR and CB1R signaling are intact in Pyr- KO}

Changes in abundance or function of CB1Rs in Pyr-KO hippocampus could explain why hippocampal synaptic plasticity in PirB mutant mice phenocopies that in WT mice when $\mathrm{CB} 1$ receptors are blocked. We confirmed the presence of presynaptically-located CB1Rs in glutamatergic terminals $[43,44]$ in P90 hippocampus - an age when CB1 receptors and $\mathrm{eCB}$ signaling are mature $[45,46]$. In high resolution immunofluorescence images, using an antibody raised against CB1R combined with immunostaining for VGlut1 (a presynaptic marker of excitatory synapses; Fig. 4a), we observed that CB1R is present at a subset of CA3 boutons, as previously described [43]. In addition, CB1R immunostaining is associated with axonal varicosities and puncta, and is particularly abundant in CA1 st. pyramidale, as expected from its well-known expression on GABAergic presynaptic terminals (Fig. S6) [43]. Western Blot analysis indicates that CB1R protein levels are comparable in Pyr-KO vs. Pyr-WT (Fig. 4b). Thus, CB1R expression or protein localization is not significantly altered in the absence of PirB.

To test if functional activation of CB1R is altered in Pyr$\mathrm{KO}$, a chemical LTD paradigm was used. Activation of CB1R with bath application of the high-affinity agonist WIN-55,212-2 is known to generate LTD at CA3-CA1 synapses (Fig. 4c, d) due entirely to a decrease in glutamate release and is thus purely presynaptic [34, 47, 48]. WIN55,212-2 generates chemical LTD (WIN-LTD) in both Pyr$\mathrm{KO}$ and Pyr-WT mice to a similar degree (Fig. 4d). PPR is also increased in both genotypes after WIN application, as expected (Fig. 4e). These observations suggest that CB1R receptors are fully functional in Pyr-KO, and that signaling downstream of CB1R is also intact. Finally, the presence of intact WIN-evoked chemical LTD in Pyr-KO suggests that eCB signaling during synaptically-induced LTD is disrupted prior to the engagement of CB1Rs.

Group I mGluRs and NMDA receptors act upstream of CB1Rs, and each glutamate receptor subtype is known to trigger postsynaptic eCB release from CA1 neurons [34, 41, 49]. Group I metabotropic glutamate receptors (mGluRs) located postsynaptically are also thought to be recruited during synaptically-induced LTD under certain conditions (e.g., [50]). To test for PirB involvement in group I mGluR 
function, a chemical LTD paradigm was used again (Fig. 4f, $\mathrm{g}, \mathrm{h})$. Group I mGluR activation with the high-affinity agonist DHPG generates sustained DHPG-LTD at CA3CA1 synapses in Pyr-WT. In Pyr-KO, application of DHPG had similar effects. In addition, PPR increased about 2.5 fold during DHPG-LTD in both genotypes [51]. To test if group I mGluRs, or downstream signaling components, are also recruited during $1 \mathrm{~Hz}$ synaptically-induced LTD [34,
41], DHPG-LTD was followed by $1 \mathrm{~Hz}$ synaptic stimulation (Fig. S8 A, B): $1 \mathrm{~Hz}$ induction failed to generate additional LTD in either Pyr-WT or Pyr-KO, indicating that downstream signaling common to activation of group I mGluRs, as well as synaptically-induced LTD is intact in Pyr-KO. PPR remained elevated following $1 \mathrm{~Hz}$ stimulation in both genotypes, implying that mGluR-dependent retrograde regulation of presynaptic release is intact.

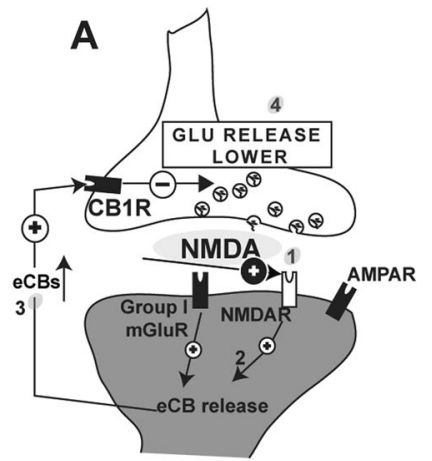

B
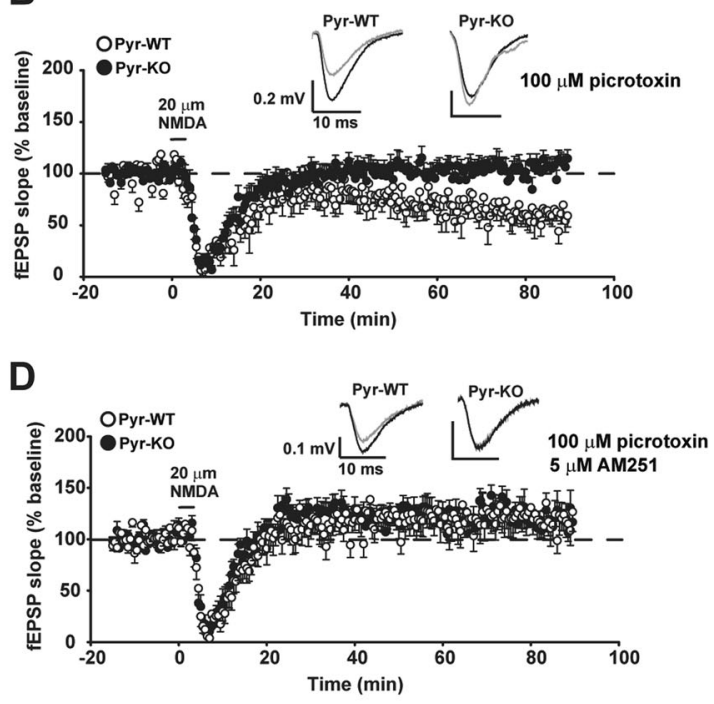

C
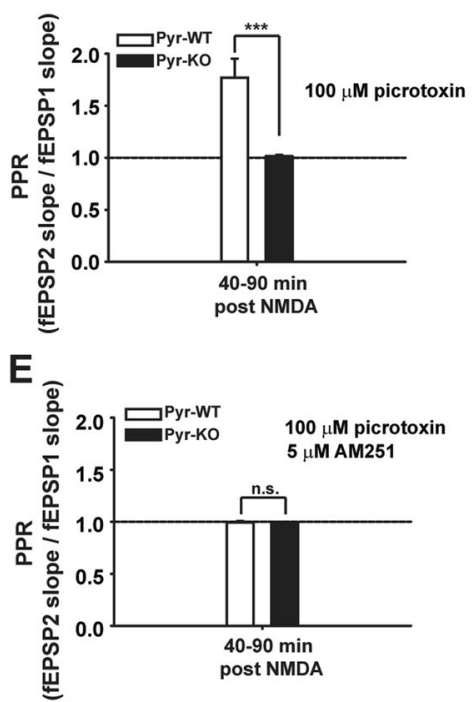

$\mathbf{F}$

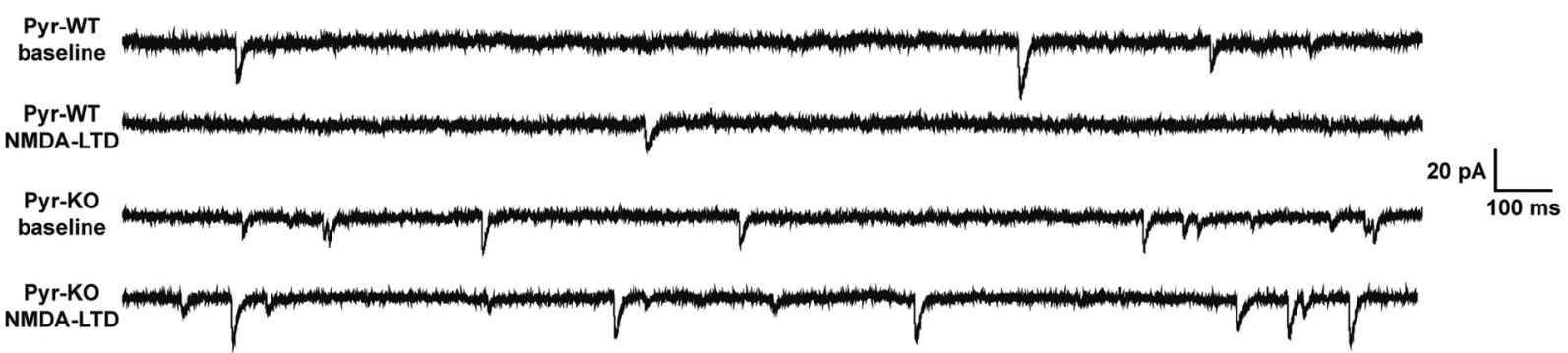

G

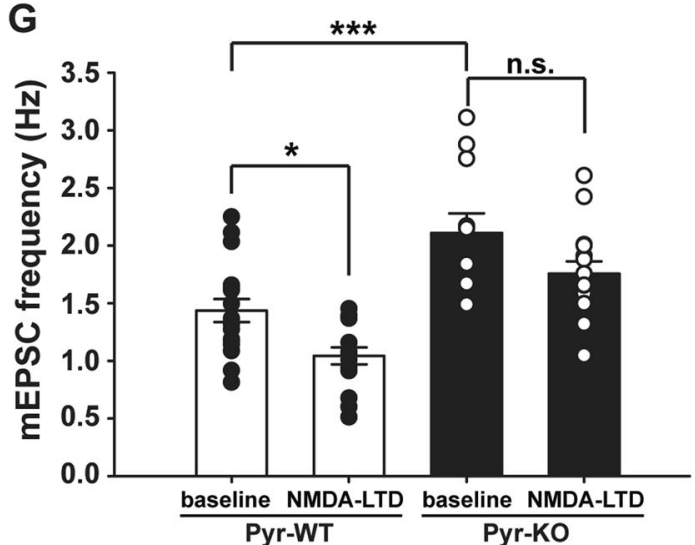

H

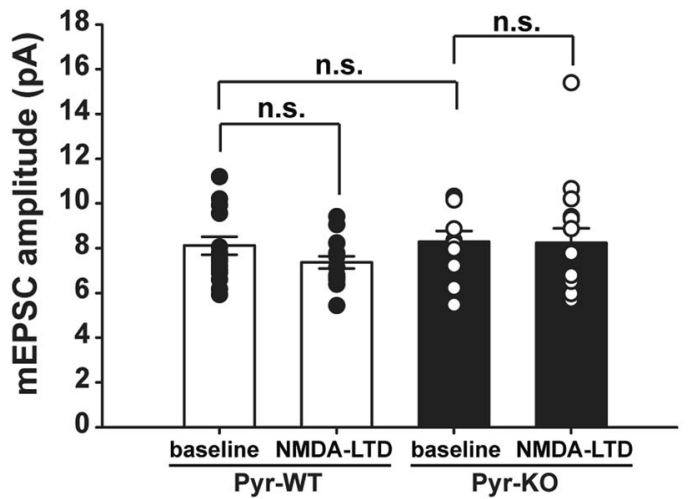


Fig. 5 NMDA-LTD and NMDA-dependent synaptic pruning is abolished in Pyr-KO mice. a Cartoon of a CA3-CA1 synapse depicting the sequential effect of bath-application of NMDA [1] on eCB release [2], activation of CB1Rs [3], and lowering glutamate release [4]. b Three minute $20 \mu \mathrm{M}$ NMDA induces persistent LTD in Pyr-WT (71.3 \pm $0.96 \% ; n=12$ slices $/ 4$ mice; $p<0.001$ relative to baseline); no effect in Pyr-KO $(103.6 \pm 1.03 \% ; n=10$ slices, 4 mice); $p<0.001,2$-Way RM Anova. c PPR for NMDA-LTD in Pyr-WT: $1.76 \pm 0.14(n=$ 12 slices $/ 4$ mice $)$ vs. Pyr-KO: $1.01 \pm 0.16(n=10$ slices, 4 mice $) ; p<$ 0.001, 2-Way RM Anova. d NMDA-LTD in Pyr-WT in the presence of $5 \mu \mathrm{M}$ AM251: $120.3 \pm 1.5 \%(n=11$ slices $/ 4$ mice $)$ vs. Pyr-KO: $122.3 \pm 1.0 \%(n=8$ slices $/ 3$ mice $) ; p=0.37,2$-Way RM Anova. e PPR during NMDA-LTD in AM251 is comparable between Pyr-WT $(0.994 \pm 0.013 ; n=11$ slices $/ 4$ mice $)$ vs. Pyr-KO $(0.99 \pm 0.015 ; n=$ 8 slices/3 mice); $p=0.73$, 2-Way RM Anova. Data averaged during period from 40 to 90 min post-induction. f Example traces of mEPSCs from Pyr-WT and Pyr-KO before and after induction of NMDA-LTD with a brief ( $3 \mathrm{~min}$ ) pulse of $20 \mu \mathrm{M}$ NMDA. g Bar-graph of average mEPSC frequency, with overlaid individual cell values (black and white symbols). Pyr-WT baseline: $1.44 \pm 0.10 \mathrm{~Hz}(n=17$ cells/ 6 mice $)$ vs. Pyr-WT NMDA-LTD: $1.04 \pm 0.07 \mathrm{~Hz}(n=15$ cells $/ 6$ mice $) ; p=$ 0.047 . Pyr-WT baseline vs. Pyr-KO baseline: $2.11 \pm 0.17 \mathrm{~Hz}(n=$ 11 cells $/ 4$ mice); $p=0.001$. Pyr-KO baseline vs. Pyr-KO NMDALTD: $1.76 \pm 0.11 \mathrm{~Hz} \quad(n=15$ cells $/ 4$ mice $) ; p=0.153$. One-Way Anova with post-hoc Tukey for multiple comparisons. h Bar-graph of average mEPSC amplitude, with overlaid individual cell values (black and white symbols). Pyr-WT baseline: 8.11 $\pm 0.41 \quad(n=17$ cells/6 mice) vs. Pyr-WT NMDA-LTD: $7.36 \pm 0.27(n=15$ cells $/ 6$ mice); $p=0.652$; Pyr-KO baseline: $8.29 \pm 0.48(n=11$ cells $/ 4$ mice $)$ vs. Pyr-KO NMDA-LTD: $8.23 \pm 0.66(n=15$ cells/4 mice); $p=1.00$. Pyr-WT baseline vs. Pyr-KO baseline: $\mathrm{p}=0.99$. One-Way Anova with post-hoc Tukey for multiple comparisons.

\section{DSI is intact at inhibitory synapses on CA1 pyramidal cells}

To assess if there might be changes in eCB release at other synapses onto CA1 pyramidal neurons in $\mathrm{Pyr}-\mathrm{KO}$, we examined a well-described eCB-dependent change in shortterm plasticity at GABAergic synapses: depolarization induced suppression of inhibition (DSI) [52]. DSI is a consequence of the retrograde effect of depolarizationinduced $\mathrm{eCB}$ release from $\mathrm{CA} 1$ pyramidal cells on presynaptic GABAergic terminals, leading to a decrease in the amplitude of IPSCs due to less GABA release [52]. Remarkably, DSI is intact in Pyr-KO, relative to Pyr-WT (Fig. S7). Thus, the retrograde effects of eCB release appear to be unaltered at inhibitory, but not excitatory, synapses on to CA1 pyramidal neurons, pointing to a restricted role of PirB at excitatory CA3 to CA1 synapses. Collectively these experiments demonstrate that CB1R function, activation of group I mGluRs, and effects of eCBs at GABAergic synapses are not affected in the absence of PirB. Moreover, they confirm a presynaptic location for $\mathrm{CB} 1$ receptors at glutamatergic CA3-CA1 Schaffer collateral synapses [34, 41, 43, 47].
Chemical NMDA-dependent LTD is abolished in PyrKO

NMDA receptors are required for induction and maintenance of LTP and LTD at excitatory synapses, including CA3-CA1 [30, 31]. Activation of NMDARs is also known to contribute to the production of eCBs in apical dendrites of CA1 neurons [49]. If PirB is part of an NMDA receptordependent mechanism for $\mathrm{eCB}$ release, then there should be a change in NMDA-dependent synaptic plasticity in the absence of PirB.

To isolate NMDA-dependent mechanisms, a chemical NMDA-LTD paradigm was used (Fig. 5a). In Pyr-WT, brief application of $20 \mu \mathrm{M}$ NMDA generates LTD at CA3-CA1 synapses (Fig. 5b), as expected [53, 54]). In contrast, in PyrKO, NMDA fails to produce sustained LTD (Fig. 5d). This result agrees well with our observation above that synaptically induced LTD in Pyr-KO is defective (Fig. 2), as well as with numerous published experimental results showing that blockade of NMDARs with MK801 or D-AP5 abolishes LTD [30, 31]. In Pyr-WT mice, PPR was increased (Fig. 5c), suggesting that bath-applied NMDA also decreases glutamate release, as expected if endocannabinoid release and retrograde signaling are NMDA-dependent [48, 49]. In Pyr-KO, PPR is unchanged with NMDA application (Fig. 5e), consistent with deficient LTD in these mice.

These differences between Pyr-KO and Pyr-WT are not due to changes in NMDA receptor abundance or function in Pyr-KO. Total protein levels of NR1, an obligatory NMDAR subunit, as well as NR2A and NR2B subunits, is comparable between Pyr-WT and Pyr-KO (Fig. S9A, B). Synaptic distribution of functional NMDARs, as assessed by measuring $\mathrm{I}_{\mathrm{AMPA}} / \mathrm{I}_{\mathrm{NMDA}}$ ratio was not changed in Pyr-KO vs. Pyr-WT (Fig. S9C). In addition, the kinetics of $\mathrm{I}_{\mathrm{NMDA}}$ decay currents were comparable between the genotypes (Fig S9D), suggesting similar composition of NR2A and NR2B subunits in Pyr-KO NMDARs, relative to Pyr-WT. Finally, blockade of $\mathrm{I}_{\text {NMDA }}$ with bath-application of a selective antagonist of NR2B- containing NMDARs, Ro 25-6981, corroborated the conclusion that NR2A/2B composition of NMDARs in PyrKO is similar to Pyr-WT (Fig. S9E).

To confirm that $\mathrm{eCB}$ signaling can be engaged in NMDA-LTD in Pyr-WT mice, in a subset of experiments CB1Rs were blocked with AM251. As expected, blockade of CB1Rs prevented maintenance of NMDA-LTD in PyrWT, without an additional effect in Pyr-KO slices (Fig. 5d). The difference in PPR between the two genotypes observed during NMDA-LTD was also abolished in the presence of AM251 (Fig. 5e). Together, these observations strongly argue that without PirB, the NMDAR-dependent regulation of LTD via endocannabinoid signaling is abrogated. 


\section{Synapse pruning driven by NMDA-dependent LTD is deficient in Pyr-KO}

It is well established that LTD, either synaptically driven or chemically induced by NMDA, results in synaptic pruning, as evidenced by direct observation of dendritic spine shrinkage and removal in an NMDA-dependent manner within an hour of LTD induction [18, 19, 55, 56]. Elimination of functional synapses can also be monitored electrophysiologically, signaled by a decrease in the frequency of mEPSCs [57]. To examine if PirB expression in CA1 neurons is needed for LTD-induced synaptic pruning, mEPSCs were monitored in Pyr-WT vs. Pyr-KO slices before and then $60 \mathrm{~min}$ after induction of NMDA-LTD (Fig. 5f-h). In Pyr-WT, a 3 min pulse of NMDA generated a $30 \%$ decrease in mEPSC frequency (Fig. 5f, g), similar to previous reports [57]. In contrast, in Pyr-KO mEPSC frequency at baseline was already higher than that of Pyr-WT by about $50 \%$, and remained unchanged even after NMDA application (Fig. 5f, g). No changes were observed in the amplitude of mEPSCs following NMDA application in either genotype (Fig. 5h). Thus, postnatal deletion of PirB specifically from pyramidal neurons renders synapses resistant to activity-dependent weakening and pruning in the context of acute changes elicited by NMDA-LTD. Moreover, the presence of increased mEPSC frequency in Pyr-KO over Pyr-WT at baseline suggests that there are already more functional excitatory synapses on CA1 neurons, which could explain stronger baseline excitatory transmission (Fig. S2F), and could also contribute to better performance on DMTP (Fig. 1).

\section{CA3-specific deletion of PirB preserves NMDA-LTD}

Results suggest a model in which PirB is required postsynaptically within CA1 cells for an NMDA receptordependent $\mathrm{eCB}$ regulation of synaptic plasticity, and for the capacity of synapses to generate LTD (Figs. 2-5f). To further address the question of pre- vs. postsynaptic site of action of PirB in adult hippocampal plasticity, the NMDALTD plasticity paradigm was repeated, but this time in a mouse line in which PirB has been deleted only from CA3; this is in contrast to Pyr-KO mice, where PirB was excised both from CA3 and CA1. A line carrying a Cre-transgene driven by a CA3-specific promoter (Grik4-Cre; see SI) was crossed to PirBfl/fl mice to generate offspring carrying a deletion of PirB in $\mathrm{CA} 3$, but not CA1 pyramidal neurons (Fig. S10 A, B, C). These mice are henceforward referred to as CA3-Pyr-KO, and their WT littermates as CA3-Pyr-WT.

In CA3-Pyr-WT mice, a pulse of $20 \mu \mathrm{m}$ NMDA generates chemical LTD at CA3-CA1 synapses (about $50 \%$ decrease from baseline) (Fig. S10D), similar to thatseen in Pyr-WT (cf. Fig. 5b). In CA3-Pyr-KO, LTD indistinguishable from that seen in CA3-Pyr-WT is generated (Fig. S10D). Furthermore, in both CA3-Pyr-WT and CA3-Pyr-KO, there is a similar increase in PPR following NMDA application, consistent with the expression of LTD in both lines (Fig. S10E). Thus, when PirB deletion is restricted presynaptically to CA3 neurons, NMDA-LTD is intact. PirB might still be present in other neurons, even after deletion of PirB in CA3 or CA1 pyramidal cells, and thus somehow affect CA3-CA1 plasticity indirectly. However, in hippocampus these "other" neurons consist of inhibitory GABAergic interneurons. Because all plasticity measurements were conducted in the presence of $100 \mu \mathrm{M}$ picrotoxin, and because PirB expression in GABAergic interneurons has not been detected, it is highly unlikely that other cell types contribute to the results described here. The conclusion that postsynaptically localized PirB is needed for NMDAR-dependent plasticity at CA3-CA1 synapses is also consistent with previous observations showing that mosaic deletion of PirB in isolated layer 2/3 pyramidal neurons of visual cortex is sufficient to generate increased spine density on apical and basal dendrites, implying a postsynaptic, cellautonomous function of PirB [16]. Taken together, these observations suggest that PirB expressed postsynaptically in CA1 pyramidal cells, rather than presynaptically in CA3, is required for NMDAR-dependent LTD, and by extension, for NMDAR-dependent regulation of $\mathrm{eCB}$ signaling and Hebbian synaptic plasticity.

\section{Discussion}

The major finding of this study is that PirB is required at excitatory CA3-CA1 synapses for activity-dependent recruitment of retrograde endocannabinoid signaling, a negative feedback system that acts to limit release of neurotransmitter. In mice lacking PirB, activity-dependent modulation of synaptic transmission is altered in such a way as to phenocopy wild type CA3-CA1 synapses in which endocannabinoid receptors (CB1R) have been blocked. While it is well known that eCBs act at GABAergic synapses in hippocampus in I-LTD [37], and in DSI [52] as we have confirmed above, previous studies have also demonstrated that $\mathrm{eCBs}$ are required for synaptically-induced LTD at CA3-CA1 excitatory synapses $[34,41]$. Genetic removal or pharmacological blockade of CB1Rs renders these synapses unable to generate LTD in WT [34, 41], while LTP-inducing stimuli generate enhanced LTP [40]. These changes are exactly what were observed at CA3-CA1 synapses of mice with conditional deletion of PirB: LTD is absent across a range of plasticityinducing stimuli from $0.5 \mathrm{~Hz}$ to $100 \mathrm{~Hz}$ (Fig. 2), and in fact only LTP of different magnitudes depending on stimulation parameters is found. Results also suggest that PirB and 
eCBs are part of the same pathway, because in hippocampus of mice lacking PirB the effect of blocking CB1Rs on both LTP and LTD is occluded. Together, these observations suggest that PirB is required for LTD, and is part of a synaptic system for regulating bidirectional Hebbian synaptic plasticity at excitatory synapses.

\section{A role for PirB in NMDAR, but not group I mGluR- dependent endocannabinoid signaling}

It is remarkable that in the absence of PirB, only the NMDAR-dependent regulation of eCBs is deficient, while the group I mGluR dependent eCB pathway appears to be intact. Direct activation of Group I mGluRs with DHPG generates a similar magnitude of chemical LTD in both mutant and WT mice. However, when chemical LTD is induced by bath-applying NMDA, a high-affinity agonist of NMDA receptors, LTD was generated only in WT hippocampus, but was absent in mice lacking PirB. This observation suggests that some patterns of synaptic activity can engage eCB signaling downstream of NMDARs independently of group I mGluRs since one is PirB-dependent and the other is not. Previous studies have demonstrated the involvement of $\mathrm{Ca}^{2+}$ influx through NMDA receptors in triggering eCB release, as well as an $\mathrm{eCB}$ contribution to synaptically induced LTD at this synapse [48, 49, 58]. Our observations are entirely consistent with these studies, and also add a new molecular component to this signaling pathway: PirB.

The fact that hippocampal mGluR-dependent LTD is intact when PirB is removed from pyramidal cells argues that most if not all other postsynaptic and presynaptic components of eCB signaling are functional and independent of PirB. Whether endocannabinoid synthesis and release at CA3 to CA1 synapses is triggered by Group I mGluRs, voltage-gated calcium channels or NMDARs [34, $41,48,49]$, once released, eCBs bind to the endocannabinoid specific receptor, CB1R, located presynaptically [52]. Here we have shown that direct chemical activation of CB1R with WIN-55,212-2 results in LTD in both WT and mutant mice to the same degree. In addition, CB1R protein levels are similar in PirBKO and WT. Thus, we conclude that PirB is specifically needed to couple NMDA receptor activation to endocannabinoid retrograde signaling, implying that the regulation of $\mathrm{eCB}$ signaling downstream of glutamate receptors may be divided into PirB-independent (Group I mGluRs) and PirB-dependent (NMDA) pathways.

It is noteworthy that in the absence of PirB in pyramidal cells, there is no change in functional synaptic NMDARs, as evidenced by intact $\mathrm{I}_{\mathrm{AMPA}} / \mathrm{I}_{\mathrm{NMDA}}$ ratio at baseline, similar decay time constants of NMDA currents, as well as unchanged levels of NR2A and NR2B protein as assessed by standard physiological and biochemical protocols [59,
60]. These observations suggest that PirB acts downstream or subsequent to the activation of NMDA receptors. It is known that when PirB intracellular signaling domains (ITIMs) are phosphorylated, SHP1/2 phosphatases are recruited [14, 61]. In addition, proteomic analysis has identified an interaction between PirB and members of the protein phosphatase 2 (PP2) family including calcineurin (PP2B) (Fig. S8 in [62]) known to be critical for LTD expression [55, 63, 64]. It is possible that in the absence of PirB, there may be alterations in the association and/or synaptic localization of key phosphatases needed for LTD, including calcineurin [63], which could in turn alter intracellular signaling cascades downstream of NMDA receptors that are required for $\mathrm{eCB}$ production or release.

\section{A role for PirB in activity-dependent synaptic pruning}

PirB-specific NMDAR signaling during LTD could be tightly linked to structural changes at dendritic spines. Twophoton microscopy in organotypic hippocampal cultures has revealed that low-frequency stimulation (LFS) can enhance dendritic spine retractions [19]. The LFS-induced retraction can be blocked with APV, an NMDAR blocker, suggesting that it is an NMDAR-dependent process [19]. In addition, a study in a mouse model of Alzheimer's disease has shown that intact PirB is needed to activate cofilin [62]; actived cofilin depolymerizes F-actin and promotes spine shrinkage and retraction [55]. It is thought that calcineurin dephosphorylates cofilin to promote its actin depolymerizing activity [55, 65]. Thus, the requirement for PirB and $\mathrm{eCBs}$ in generating and sustaining NMDAR-dependent LTD at CA3-CA1 synapses could be an inextricable part of an NMDAR-specific dendritic spine retraction mechanism $[19,66]$.

Activity-dependent and NMDAR-dependent synaptic weakening and pruning can be induced in hippocampal slices using low-frequency stimulation (e.g., $1 \mathrm{~Hz}$, known to induce LTD) [18, 19, 55], as well as with chemical NMDALTD [56]. Here, in WT we find that within an hour of NMDA-LTD there is a decrease in mEPSC frequency (Fig. 5), as shown previously [57] and consistent with a loss of excitatory synapses. However, in Pyr-KO the NMDALTD-dependent decrease in mEPSC frequency is absent, suggesting that when PirB is deleted from pyramidal cells a signaling cascade needed for synaptic elimination is disengaged. In addition, the effect of postnatal PirB deletion on mEPSC frequency is evident even at baseline, prior to NMDA-LTD induction. Together, these observations suggest that without PirB, CA3 to CA1 synapses become resistant to activity-dependent pruning, growing in density to $50 \%$ greater than that in adult WT. Note that these observations here in hippocampus are consistent with 
previously observed elevated mEPSC frequency and spine density in L5 and L2/3 pyramidal neurons of visual cortex arising from impaired activity-dependent synapse pruning during the developmental critical period [15-17].

\section{Activity-dependent recruitment of PirB and downstream effectors-a model}

Here we have shown that PirB is part of an eCB signaling cascade that is recruited by activity, and in its absence, synapses cannot weaken. We propose that PirB function is needed for synapses to adjust and maintain their state to reflect their history of neural activity, while retaining their capacity for further potentiation. The requirement for PirB in bidirectional Hebbian synaptic plasticity also suggests that PirB contributes to the phenomenon of metaplasticity [67]. These considerations imply that changes in neural activity should engage PirB signaling. PirB is an MHC class I (MHCI) receptor, both in neurons and in immune cells $[13,14,62]$. MHCI molecules were discovered in an in vivo expression screen searching for genes regulated by neural activity [68]. Moreover in mice lacking stable MHCI surface expression, hippocampal LTD is absent and LTP is enhanced [54, 69], similar to what is seen here in PirB null mice and consistent with the fact that MHCI molecules bind to PirB. In vitro, MHCIs are also needed for proper activity-dependent scaling of hippocampal synapses [70].

In addition to MHCI proteins, myelin proteins including Nogo-A, OMgp and MAG have been shown to bind to PirB [71]. These ligand-receptor interactions elicit growth cone collapse in vitro [71], and possibly in vivo [72]. In the context of learning and plasticity, multiple independent studies have implicated all three myelin based proteins in negative regulation of ocular dominance plasticity [73], learning processes during fear extinction [74], and synaptic plasticity [75] in adult animals. Even though most of these effects seem to be mediated via Nogo-receptor 1 (NGR1) [73-75], an OMgp-PirB interaction has been implicated in the negative regulation of hippocampal LTP in adult mice [75]. It would be interesting to know if Nogo-A, OMgp, or MAG levels are regulated by neural activity, as is the case for the MHC class I ligands. Together, our current findings suggest a model (Fig. S11) in which PirB signaling is modulated by activity-dependent changes in MHCI levels, which in turn affect intracellular signaling cascades downstream of NMDA receptors required for LTD and $\mathrm{eCB}$ production and release.

Acknowledgements We wish to thank Drs. Daniel Madison and Lisa Giocomo (Stanford University) for advice on hippocampal synaptic plasticity, Dr. Kylie Chew and Richie Sapp for critical reading of the manuscript, and Nora Sotelo-Kury, Peggy Kemper, and Christina Chechelski for technical support. Special thanks to Dr. Ken Mackie
(Indiana University at Bloomington, IN) for a gift of the CB1R antibody, and Dr. Liqun Luo (Stanford University, Stanford, CA) for Ai14TdTomato breeder mice. This project was supported by NIH grants EY02858 and MH07166, the Mathers Charitable Foundation and the Rosenberg Family Foundation to CJS.

Author contributions MD designed, executed, and analyzed all the physiology, histology, and immunofluorescence experiments. BKB performed biochemical essays and Western Blot protein analysis; MS and NLS designed executed and analyzed behavioral experiments. CJS advised on experimental design and analysis, and MD and CJS wrote the manuscript.

\section{Compliance with ethical standards}

Conflict of interest The authors declare that they have no conflict of interest.

Open Access This article is licensed under a Creative Commons Attribution 4.0 International License, which permits use, sharing, adaptation, distribution and reproduction in any medium or format, as long as you give appropriate credit to the original author(s) and the source, provide a link to the Creative Commons license, and indicate if changes were made. The images or other third party material in this article are included in the article's Creative Commons license, unless indicated otherwise in a credit line to the material. If material is not included in the article's Creative Commons license and your intended use is not permitted by statutory regulation or exceeds the permitted use, you will need to obtain permission directly from the copyright holder. To view a copy of this license, visit http://creativecommons. org/licenses/by/4.0/.

\section{References}

1. Shi J, Levinson DF, Duan J, Sanders AR, Zheng Y, Pe'er I, et al. Common variants on chromosome $6 \mathrm{p} 22.1$ are associated with schizophrenia. Nature. 2009;460:753-7.

2. Stefansson H, Ophoff RA, Steinberg S, Andreassen OA, Cichon $\mathrm{S}$, Rujescu D, et al. Common variants conferring risk of schizophrenia. Nature. 2009;460:744-7.

3. Sinkus ML, Adams CE, Logel J, Freedman R, Leonard S. Expression of immune genes on chromosome 6p21.3-22.1 in schizophrenia. Brain Behav Immun. 2013;32:51-62.

4. Stevens B, Allen NJ, Vazquez LE, Howell GR, Christopherson KS, Nouri N, et al. The classical complement cascade mediates CNS synapse elimination. Cell. 2007;131:1164-78.

5. Sekar A, Bialas AR, de Rivera H, Davis A, Hammond TR, Kamitaki N, et al. Schizophrenia risk from complex variation of complement component 4. Nature. 2016;530:177-83.

6. Morgan LZ, Rollins B, Sequeira A, Byerley W, DeLisi LE, Schatzberg AF, et al. Quantitative trait locus and brain expression of HLA-DPA1 offers evidence of shared immune alterations in psychiatric disorders. Microarrays. 2016;5:1-25

7. Needleman LA, Liu XB, El-Sabeawy F, Jones EG, McAllister AK. MHC class I molecules are present both pre- and postsynaptically in the visual cortex during postnatal development and in adulthood. Proc Natl Acad Sci USA. 2010;107:16999-7004.

8. Datwani A, McConnell MJ, Kanold PO, Micheva KD, Busse B, Shamloo M, et al. Classical MHCI molecules regulate retinogeniculate refinement and limit ocular dominance plasticity. Neuron. 2009;64:463-70.

9. McConnell MJ, Huang YH, Datwani A, Shatz CJ. H2-K(b) andH2-D(b) regulate cerebellar long-term depression and limit motor learning. Proc Natl Acad Sci USA. 2009;106:6784-9. 
10. Hong S, Beja-Glasser VF, Nfonoyim BM, Frouin A, Li S, Ramakrishnan S, et al. Complement and microglia mediate early synapse loss in Alzheimer mouse models. Science. 2016;352: 712-6.

11. Lee H, Brott BK, Kirkby LA, Adelson JD, Cheng S, Feller MB, et al. Synapse elimination and learning rules co-regulated by MHC class I H2-Db. Nature. 2014;509:195-200.

12. Glausier JR, Lewis DA. Dendritic spine pathology in schizophrenia. Neuroscience. 2013;251:90-107.

13. Nakamura A, Kobayashi E, Takai T. Exacerbated graft-versushost disease in Pirb-/- mice. Nat Immunol. 2004;5:623-9.

14. Syken J, Grandpre T, Kanold PO, Shatz CJ. PirB restricts oculardominance plasticity in visual cortex. Science. 2006;313: $1795-1800$.

15. Djurisic M, Vidal GS, Mann M, Aharon A, Kim T, Ferrao Santos A, et al. PirB regulates a structural substrate for cortical plasticity. Proc Natl Acad Sci USA. 2013;110:20771-6.

16. Vidal GS, Djurisic M, Brown K, Sapp RW, Shatz CJ. Cellautonomous regulation of dendritic spine density by PirB. eNeuro. 2016;3:1-15

17. Bochner DN, Sapp RW, Adelson JD, Zhang S, Lee H, Djurisic M, et al. Blocking PirB up-regulates spines and functional synapses to unlock visual cortical plasticity and facilitate recovery from amblyopia. Sci Transl Med. 2014;6:258ra140.

18. Bastrikova N, Gardner GA, Reece JM, Jeromin A, Dudek SM. Synapse elimination accompanies functional plasticity in hippocampal neurons. Proc Natl Acad Sci USA. 2008; 105:3123-7.

19. Nagerl UV, Eberhorn N, Cambridge SB, Bonhoeffer T. Bidirectional activity-dependent morphological plasticity in hippocampal neurons. Neuron. 2004;44:759-67.

20. Engert F, Bonhoeffer T. Dendritic spine changes associated with hippocampal long-term synaptic plasticity. Nature. 1999;399:66-70.

21. Faizi M, Bader PL, Saw N, Nguyen TV, Beraki S, Wyss-Coray T, et al. Thy1-hAPP(Lond/Swe +) mouse model of Alzheimer's disease displays broad behavioral deficits in sensorimotor, cognitive and social function. Brain Behav. 2012;2:142-54.

22. Steele RJ, Morris RG. Delay-dependent impairment of a matching-to-place task with chronic and intrahippocampal infusion of the NMDA-antagonist D-AP5. Hippocampus. 1999;9: $118-36$

23. Tsien JZ, Huerta PT, Tonegawa S. The essential role of hippocampal CA1 NMDA receptor-dependent synaptic plasticity in spatial memory. Cell. 1996;87:1327-38.

24. Tonegawa S, Tsien JZ, McHugh TJ, Huerta P, Blum KI, Wilson MA. Hippocampal CA1-region-restricted knockout of NMDAR1 gene disrupts synaptic plasticity, place fields, and spatial learning. Cold Spring Harb Symp Quant Biol. 1996; 61:225-38.

25. Silva AJ, Rosahl TW, Chapman PF, Marowitz Z, Friedman E, Frankland PW, et al. Impaired learning in mice with abnormal short-lived plasticity. Curr Biol. 1996;6:1509-18.

26. Ohno M, Sametsky EA, Silva AJ, Disterhoft JF. Differential effects of alphaCaMKII mutation on hippocampal learning and changes in intrinsic neuronal excitability. Eur $\mathrm{J}$ Neurosci. 2006;23:2235-40.

27. Dobrunz LE, Stevens CF. Heterogeneity of release probability, facilitation, and depletion at central synapses. Neuron. 1997;18:995-1008.

28. Lee YS, Silva AJ. The molecular and cellular biology of enhanced cognition. Nat Rev Neurosci. 2009;10:126-40.

29. Malleret G, Haditsch U, Genoux D, Jones MW, Bliss TV, Vanhoose AM, et al. Inducible and reversible enhancement of learning, memory, and long-term potentiation by genetic inhibition of calcineurin. Cell. 2001;104:675-86.
30. Heynen AJ, Abraham WC, Bear MF. Bidirectional modification of CA1 synapses in the adult hippocampus in vivo. Nature. 1996;381:163-6.

31. Babiec WE, Guglietta R, Jami SA, Morishita W, Malenka RC, O'Dell TJ. Ionotropic NMDA receptor signaling is required for the induction of long-term depression in the mouse hippocampal CA1 region. J Neurosci. 2014;34:5285-90.

32. Dudek SM, Bear MF. Homosynaptic long-term depression in area CA1 of hippocampus and effects of N-methyl-D-aspartate receptor blockade. Proc Natl Acad Sci USA. 1992;89:4363-7.

33. Jackman SL, Regehr WG. The mechanisms and functions of synaptic facilitation. Neuron. 2017;94:447-64.

34. Izumi Y, Zorumski CF. NMDA receptors, mGluR5, and endocannabinoids are involved in a cascade leading to hippocampal longterm depression. Neuropsychopharmacology. 2011;37:609-17.

35. Manabe T, Wyllie DJ, Perkel DJ, Nicoll RA. Modulation of synaptic transmission and long-term potentiation: effects on paired pulse facilitation and EPSC variance in the CA1 region of the hippocampus. J Neurophysiol. 1993;70:1451-9.

36. Chevaleyre V, Castillo PE. Endocannabinoid-mediated metaplasticity in the hippocampus. Neuron. 2004;43:871-81.

37. Chevaleyre V, Castillo PE. Heterosynaptic LTD of hippocampal GABAergic synapses: a novel role of endocannabinoids in regulating excitability. Neuron. 2003;38:461-72.

38. Yasuda H, Huang Y, Tsumoto T. Regulation of excitability and plasticity by endocannabinoids and PKA in developing hippocampus. Proc Natl Acad Sci USA. 2008;105:3106-11.

39. Younts TJ, Chevaleyre V, Castillo PE. CA1 pyramidal cell thetaburst firing triggers endocannabinoid-mediated long-term depression at both somatic and dendritic inhibitory synapses. J Neurosci. 2013;33:13743-57.

40. Monory K, Polack M, Remus A, Lutz B, Korte M. Cannabinoid CB1 receptor calibrates excitatory synaptic balance in the mouse hippocampus. J Neurosci. 2015;35:3842-50.

41. Peterfi Z, Urban GM, Papp OI, Nemeth B, Monyer H, Szabo G, et al. Endocannabinoid-mediated long-term depression of afferent excitatory synapses in hippocampal pyramidal cells and GABAergic interneurons. J Neurosci. 2012;32:14448-63.

42. Wilson RI, Nicoll RA. Endogenous cannabinoids mediate retrograde signalling at hippocampal synapses. Nature. 2001;410:588-92.

43. Monory K, Massa F, Egertova M, Eder M, Blaudzun H, Westenbroek R, et al. The endocannabinoid system controls key epileptogenic circuits in the hippocampus. Neuron. 2006;51:455-66.

44. Lovelace JW, Corches A, Vieira PA, Hiroto AS, Mackie K, Korzus E. An animal model of female adolescent cannabinoid exposure elicits a long-lasting deficit in presynaptic long-term plasticity. Neuropharmacology. 2015;99:242-55.

45. Rodriguez de Fonseca F, Ramos JA, Bonnin A, Fernandez-Ruiz JJ. Presence of cannabinoid binding sites in the brain from early postnatal ages. Neuroreport. 1993;4:135-8.

46. Piyanova A, Lomazzo E, Bindila L, Lerner R, Albayram O, Ruhl $\mathrm{T}$, et al. Age-related changes in the endocannabinoid system in the mouse hippocampus. Mech Ageing Dev. 2015;150:55-64.

47. Domenici MR, Azad SC, Marsicano G, Schierloh A, Wotjak CT, Dodt HU, et al. Cannabinoid receptor type 1 located on presynaptic terminals of principal neurons in the forebrain controls glutamatergic synaptic transmission. J Neurosci. 2006;26:5794-9.

48. Xu JY, Chen R, Zhang J, Chen C. Endocannabinoids differentially modulate synaptic plasticity in rat hippocampal CA1 pyramidal neurons. PLoS One. 2010;5:e10306.

49. Ohno-Shosaku T, Hashimotodani Y, Ano M, Takeda S, Tsubokawa $\mathrm{H}$, Kano $\mathrm{M}$. Endocannabinoid signalling triggered by NMDA receptor-mediated calcium entry into rat hippocampal neurons. J Physiol. 2007;584(Pt 2):407-18.

50. Izumi Y, Zorumski CF. GABA and Endocannabinoids Mediate Depotentiation of Schaffer Collateral Synapses Induced by 
Stimulation of Temperoammonic Inputs. PLoS One. 2016;11: e0149034.

51. Mannaioni G, Marino MJ, Valenti O, Traynelis SF, Conn PJ. Metabotropic glutamate receptors 1 and 5 differentially regulate CA1 pyramidal cell function. J Neurosci. 2001;21:5925-34.

52. Wilson RI, Kunos G, Nicoll RA. Presynaptic specificity of endocannabinoid signaling in the hippocampus. Neuron. 2001;31:453-62.

53. Zhang XL, Zhou ZY, Winterer J, Muller W, Stanton PK. NMDAdependent, but not group I metabotropic glutamate receptordependent, long-term depression at Schaffer collateral-CA1 synapses is associated with long-term reduction of release from the rapidly recycling presynaptic vesicle pool. J Neurosci. 2006;26:10270-80.

54. Nelson PA, Sage JR, Wood SC, Davenport CM, Anagnostaras SG, Boulanger LM. MHC class I immune proteins are critical for hippocampus-dependent memory and gate NMDAR-dependent hippocampal long-term depression. Learn Mem. 2013;20:505-17.

55. Zhou Q, Homma KJ, Poo MM. Shrinkage of dendritic spines associated with long-term depression of hippocampal synapses. Neuron. 2004;44:749-57.

56. Calabrese B, Saffin JM, Halpain S. Activity-dependent dendritic spine shrinkage and growth involve downregulation of cofilin via distinct mechanisms. PLoS One. 2014;9:e94787.

57. Beattie EC, Carroll RC, Yu X, Morishita W, Yasuda H, von Zastrow M, et al. Regulation of AMPA receptor endocytosis by a signaling mechanism shared with LTD. Nat Neurosci. 2000;3:1291-1300

58. Hashimotodani Y, Ohno-Shosaku T, Watanabe M, Kano M. Roles of phospholipase Cbeta and NMDA receptor in activity-dependent endocannabinoid release. J Physiol. 2007;584(Pt 2):373-80.

59. Cho KK, Khibnik L, Philpot BD, Bear MF. The ratio of NR2A/B NMDA receptor subunits determines the qualities of ocular dominance plasticity in visual cortex. Proc Natl Acad Sci USA. 2009;106:5377-82.

60. Morishita W, Lu W, Smith GB, Nicoll RA, Bear MF, Malenka RC. Activation of NR2B-containing NMDA receptors is not required for NMDA receptor-dependent long-term depression. Neuropharmacology. 2007;52:71-6.

61. Maeda A, Kurosaki M, Ono M, Takai T, Kurosaki T. Requirement of SH2-containing protein tyrosine phosphatases SHP-1 and SHP2 for paired immunoglobulin-like receptor B (PIR-B)-mediated inhibitory signal. J Exp Med. 1998;187:1355-60.

62. Kim T, Vidal GS, Djurisic M, William CM, Birnbaum ME, Garcia $\mathrm{KC}$, et al. Human LilrB2 is a beta-amyloid receptor and its murine homolog PirB regulates synaptic plasticity in an Alzheimer's model. Science. 2013;341:1399-404.

63. Mulkey RM, Endo S, Shenolikar S, Malenka RC. Involvement of a calcineurin/inhibitor-1 phosphatase cascade in hippocampal long-term depression. Nature. 1994;369:486-8.

64. Zeng H, Chattarji S, Barbarosie M, Rondi-Reig L, Philpot BD, Miyakawa $\mathrm{T}$, et al. Forebrain-specific calcineurin knockout selectively impairs bidirectional synaptic plasticity and working/ episodic-like memory. Cell. 2001;107:617-29.

65. Shankar GM, Bloodgood BL, Townsend M, Walsh DM, Selkoe DJ, Sabatini BL. Natural oligomers of the Alzheimer amyloid-beta protein induce reversible synapse loss by modulating an NMDAtype glutamate receptor-dependent signaling pathway. J Neurosci. 2007;27:2866-75

66. Becker N, Wierenga CJ, Fonseca R, Bonhoeffer T, Nagerl UV. LTD induction causes morphological changes of presynaptic boutons and reduces their contacts with spines. Neuron. 2008;60:590-7.

67. Abraham WC, Bear MF. Metaplasticity: the plasticity of synaptic plasticity. Trends Neurosci. 1996;19:126-30.

68. Corriveau RA, Huh GS, Shatz CJ. Regulation of class I MHC gene expression in the developing and mature CNS by neural activity. Neuron. 1998;21:505-20.

69. Huh GS, Boulanger LM, Du H, Riquelme PA, Brotz TM, Shatz CJ. Functional requirement for class I MHC in CNS development and plasticity. Science. 2000;290:2155-9.

70. Goddard CA, Butts DA, Shatz CJ. Regulation of CNS synapses by neuronal MHC class I. Proc Natl Acad Sci USA. 2007;104:6828-33.

71. Atwal JK, Pinkston-Gosse J, Syken J, Stawicki S, Wu Y, Shatz C, et al. PirB is a functional receptor for myelin inhibitors of axonal regeneration. Science. 2008;322:967-70.

72. Adelson JD, Barreto GE, Xu L, Kim T, Brott BK, Ouyang YB, et al. Neuroprotection from stroke in the absence of MHCI or PirB. Neuron. 2012;73:1100-7.

73. McGee AW, Yang Y, Fischer QS, Daw NW, Strittmatter SM. Experience-driven plasticity of visual cortex limited by myelin and Nogo receptor. Science. 2005;309:2222-6.

74. Bhagat SM, Butler SS, Taylor JR, McEwen BS, Strittmatter SM. Erasure of fear memories is prevented by Nogo Receptor 1 in adulthood. Mol Psychiatry. 2016;21:1281-9.

75. Raiker SJ, Lee H, Baldwin KT, Duan Y, Shrager P, Giger RJ. Oligodendrocyte-myelin glycoprotein and Nogo negatively regulate activity-dependent synaptic plasticity. J Neurosci. 2010;30:12432-45. 